Archive for

Organic Chemistry

Arkivoc 2018, part vii, 0-0

\title{
An efficient synthesis and antimicrobial evaluation of 5-alkenyl- and 5-styryl- 1,2,4-oxadiazoles
}

\section{Marina Tarasenko, ${ }^{* a}$ Vera Sidneva, ${ }^{a}$ Alexandra Belova,b Anna Romanycheva, ${ }^{\mathrm{b}}$ Tatyana Sharonova, ${ }^{\mathrm{c}}$ Sergey Baykov, ${ }^{c}$ Anton Shetnev, ${ }^{b}$ Eugeniy Kofanov, ${ }^{a}$ and Mikhail A. Kuznetsov ${ }^{c}$ \\ ${ }^{a}$ Department of Organic and Analytical Chemistry, Yaroslavl State Technical University, Yaroslavl, Russian Federation \\ ${ }^{b}$ Pharmaceutical Technology Transfer Center, Ushinsky Yaroslavl State Pedagogical University, Yaroslavl, Russian Federation \\ 'Institute of Chemistry, Saint Petersburg State University, Saint Petersburg, Russian Federation}

Email:mkarunnaya@mail.ru

Received 09-20-2018

Accepted 12-03-2018

Published on line 12-27-2018

\section{Abstract}

The cyclodehydration of $\mathrm{O}$-acylamidoximes at room temperature in the superbase system $\mathrm{KOH} / \mathrm{DMSO}$ represents a simple and efficient way to 5-alkenyl- and 5-styryl-1,2,4-oxadiazoles. This method is suitable for the preparation of 5-(4-vinylphenyl)-1,2,4-oxadiazoles as well. Results of the antimicrobial tests demonstrated that the synthesized compounds exhibit a moderate antimicrobial effect against E.coli, S.aureus and C.albicans strains.
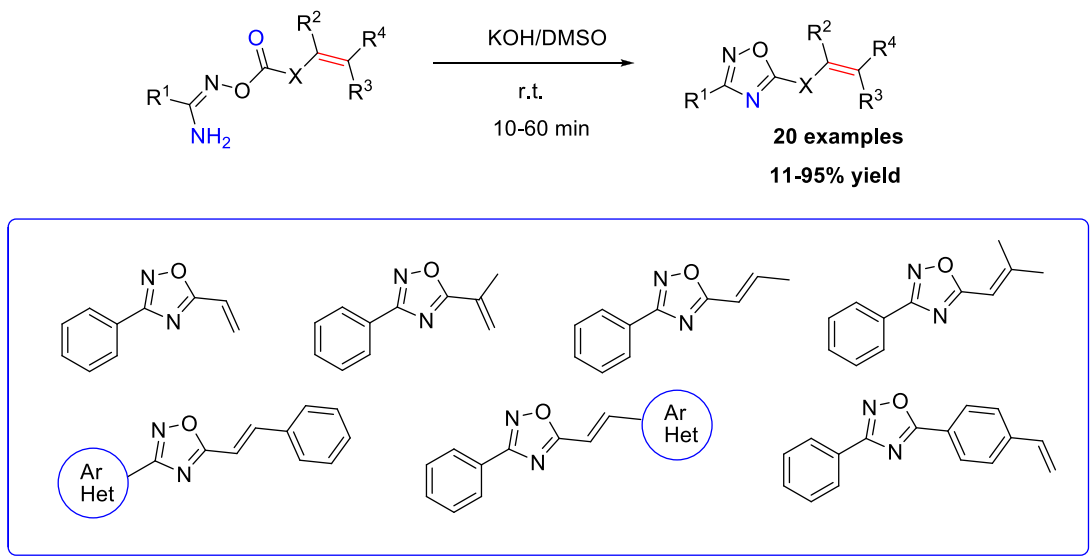

Keywords: Heterocycles, $\mathrm{O}$-acylamidoximes, cyclodehydration, base catalysis, antimicrobial activity 


\section{Introduction}

3,5-Disubstituted-1,2,4-oxadiazoles are widely used both in pharmaceutical research and for the development of new materials. ${ }^{1-4}$ In particular, compounds bearing a carbon-carbon double bond in the 5-position of the heterocyclic ring are agonists of the central nicotinic acetylcholine receptors ${ }^{5}$, PDE-4 inhibitors ${ }^{6-8}$, nonnucleoside antivirals ${ }^{9}$, antiplasmodials ${ }^{10}$ and antiproliferative agents (Fig. 1). ${ }^{11}$ Moreover, 5-alkenyl- and 5styryl-1,2,4-oxadiazoles are actively employed in organic synthesis, including Michael addition reactions ${ }^{12-14}$, 1,3-dipolar cycloadditions ${ }^{15,16}$, Rh-catalyzed ${ }^{17,18}$ or metal-free arylations. ${ }^{19}$

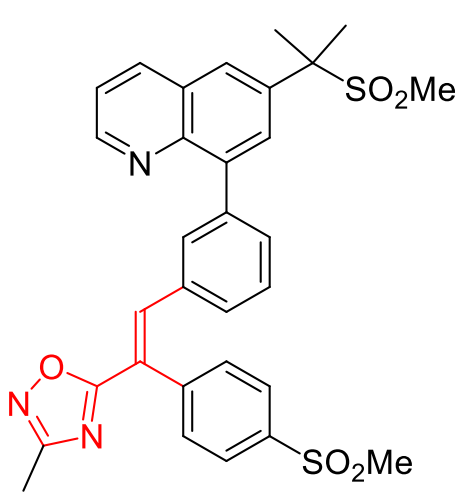

PDE-4 inhibitor ${ }^{3}$<smiles>Clc1ccc(-c2noc(/C=C/c3ccc(Br)s3)n2)cc1</smiles>

Dengue virus inhibitor ${ }^{4}$<smiles>Cn1cc(-c2noc(C=C(n3ccnc3)n3ccnc3)n2)c2cc(Cl)ccc21</smiles>

Antiproliferative agent ${ }^{6}$

Figure 1. Examples of biologically active 5-alkenyl- and 5-styryl-1,2,4-oxadiazoles.

Most of the traditional methods for the preparation of 1,2,4-oxadiazole, such as condensation of amidoximes with carboxylic acids and their derivatives or 1,3-dipolar cycloadditions of nitrile oxides to nitriles, ${ }^{20-23}$ require harsh conditions (high temperature, microwave irradiation or high pressure). ${ }^{24,25}$ These conditions pose a serious limitation for labile organic compounds, especially those containing $\mathrm{C}=\mathrm{C}$ double bonds and typically yield multiple side-products along with low yields of target compounds. ${ }^{26-30}$ For this reason, novel synthetic approaches to 1,2,4-oxadiazoles, operating under mild conditions, have been actively developing in recent years. ${ }^{31-33}$

Previously, we have reported that the $\mathrm{MOH} / \mathrm{DMSO}(\mathrm{M}=\mathrm{Li}, \mathrm{Na}, \mathrm{K})$ system is an efficient medium for the synthesis of 1,2,4-oxadiazoles at ambient temperature. ${ }^{34-37}$ While many substrates with aliphatic, aromatic and heterocyclic substituents have been studied, those with alkenyl and styryl groups were not. Herein, we describe an efficient and practical cyclodehydration of $O$-acylamidoximes with alkenyl- and styryl- moieties that occurs in $\mathrm{KOH} / \mathrm{DMSO}$ medium.

\section{Results and Discussion}

\section{Synthesis of 5-alkenyl- and 5-styryl-1,2,4-oxadiazoles (4)}

The starting $O$-acylamidoximes (3a-p) were synthesized from commercial nitriles in two steps (Scheme 1). 


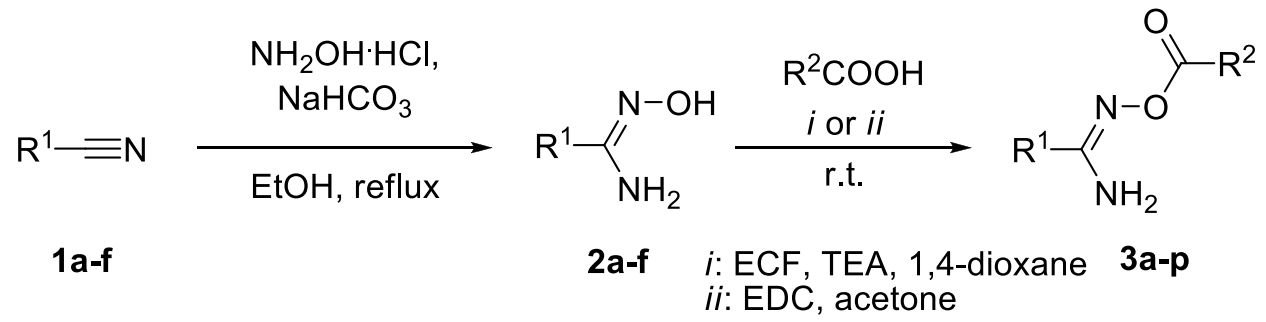

Scheme 1: Synthetic scheme for generation of the $O$-acylamidoximines (3a-p)

The $\mathbf{O}$-acylamidoximes 3a-p were then converted to the corresponding substituted 1,2,4-oxadiazoles in generally good yields under mild conditions (Scheme $\mathbf{2}$ and Table $\mathbf{1}$ ).

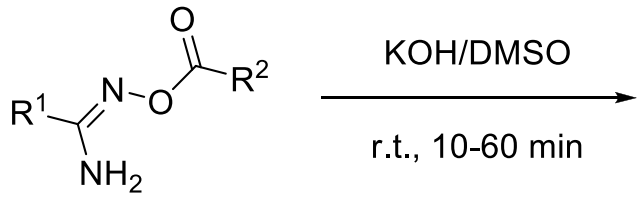

3a-p

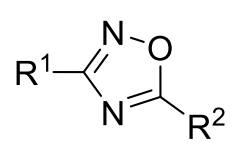

4a-p

Scheme 2: Synthetic scheme for generation of the corresponding substituted-1,2,4-oxadiazpless from the corresponding $O$-acylamidoximines (3a-p)

At the onset of our study, we investigated the cyclodehydration of the acrylic acid derivative 3a (Table 1, entries 1 and 2). Initially, an equimolar ratio of the $O$-acylamidoxime and $\mathrm{KOH}$ was used ${ }^{38}$, and the reaction was carried out for 10 minutes. The targeted 5-vinyl-1,2,4-oxadiazole is a colorless liquid. ${ }^{26-30}$ The isolated white powder contained no carbon-carbon double bond according to the IR spectrum. Moreover, the molecular weight of this solid is $\sim 450 \mathrm{kDa}$ (by GPC), suggesting that the material formed is a product of the base-initiated anionic polymerization (anionic polymerization of Michael acceptors in DMSO is known) ${ }^{39,40}$

Reducing the amount of $\mathrm{KOH}$ to 0.1 equiv. decreases the reaction rate and allows isolation of the desired 4a after column chromatography, albeit in low (11\%) yield (Table 1, entry 2). Similar results were obtained for the methacrylic derivative $\mathbf{3 b}$ (Table 1, entries 3 and 4). On the contrary, crotonic and methylcrotonic derivatives $\mathbf{4 c}$ and $\mathbf{4 d}$ were obtained in good yields ( 79 and $80 \%$, respectively) with 0.1 equiv. of $\mathrm{KOH}$ (Table 1 , entries 6 and 8). The cyclodehydration of $O$-acylamidoximes 3e-n was successful with 1 equiv. of $\mathrm{KOH}$ (with the single exception of $\mathbf{3 k}$ ), furnishing good to excellent yields of desired 1,2,4-oxadiazoles (Table 1, entries 921). Our results demonstrate that the presence of alkyl, aryl or heteroaryl substituents at the terminal carbon atom of the double bond reduces the polymerization tendency of 1,2,4-oxadiazoles.

Furthermore, we applied our protocol for the preparation of 5-(4-vinylphenyl)-1,2,4-oxadiazoles. These compounds are only poorly studied, presumably because their synthesis is rather tedious and given that the vinyl group is unstable under thermal cyclodehydration conditions. ${ }^{41}$ For this reason, alternative approaches such as the Wittig and Stille reactions or the reduction of the appropriate alkyne ${ }^{41,42}$ were utilized for the synthesis of 1,2,4-oxadiazoles with vinylphenyl moiety. Noteworthy, compounds 40 and $4 \mathrm{p}$ were prepared in good yields according to our method (Table 1, entries 22 and 23). 
Table 1. Results of cyclodehydration of $O$-acylamidoximes (3a-p) to the corresponding oxadiazoles (4a-p).

\begin{tabular}{|c|c|c|c|c|c|c|c|}
\hline Entry & $O$-acylamidoxime & $\mathrm{R}_{1}$ & $\mathrm{R}_{2}$ & $\begin{array}{c}\text { Amount of } \\
\mathrm{KOH}\end{array}$ & $\begin{array}{l}\text { Reaction } \\
\text { time, min }\end{array}$ & Product & $\begin{array}{c}\text { Yield, } \\
\%\end{array}$ \\
\hline 1 & \multirow{2}{*}{$3 a$} & & & 1.0 & 10 & \multirow{2}{*}{$4 a$} & - \\
\hline 2 & & & & 0.1 & 30 & & 11 \\
\hline 3 & \multirow{2}{*}{$3 b$} & & & 1.0 & 10 & \multirow{2}{*}{$4 b$} & - \\
\hline 4 & & & & 0.1 & 30 & & 15 \\
\hline 5 & \multirow{2}{*}{$3 c$} & & & 1.0 & 10 & \multirow{2}{*}{ 4c } & - \\
\hline 6 & & & & 0.1 & 30 & & 79 \\
\hline 7 & \multirow{2}{*}{$3 d$} & & & 1.0 & 10 & \multirow{2}{*}{$4 d$} & - \\
\hline 8 & & & & 0.1 & 30 & & 80 \\
\hline 9 & $3 e$ & & & 1.0 & 10 & $4 e$ & 87 \\
\hline 10 & $3 f$ & & & 1.0 & 10 & $4 f$ & 88 \\
\hline 11 & $3 g$ & & & 1.0 & 10 & $4 g$ & 80 \\
\hline 12 & $3 h$ & & & 1.0 & 10 & $4 h$ & 82 \\
\hline 13 & $3 i$ & & & 1.0 & 10 & $4 \mathbf{i}$ & 80 \\
\hline 14 & $3 j$ & & & 1.0 & 10 & $4 j$ & 79 \\
\hline 15 & & & & 1.0 & 10 & $4 k$ & 35 \\
\hline 16 & $3 k$ & & & 0.1 & 60 & $4 k$ & 85 \\
\hline 17 & & & & 1.0 & 10 & 41 & 78 \\
\hline 18 & 31 & & & 0.1 & 60 & 41 & 78 \\
\hline 19 & $3 m$ & & & 1.0 & 20 & $4 m$ & 86 \\
\hline 20 & $3 m$ & & & 0.1 & 60 & $4 m$ & 95 \\
\hline 21 & $3 n$ & & & 1.0 & 10 & $4 n$ & 74 \\
\hline 22 & 30 & & & 1.0 & 10 & 40 & 88 \\
\hline 23 & $3 p$ & & & 1.0 & 10 & $4 p$ & 85 \\
\hline
\end{tabular}

A broad spectrum of compounds based on the 1,2,4-oxadiazole scaffold are well known as potent antimicrobial agents. ${ }^{43}$ No antibacterial studies of $1,2,4$-oxadiazoles containing a $\mathrm{C}=\mathrm{C}$ double bond, however, have, hitherto, been conducted. Motivated by this, we assessed the antibacterial and antifungal activities of synthesized heterocycles against Staphylococcus aureus, Escherichia coli, and Candida albicans by the broth double microdilution method. ${ }^{44,45}$ 


\section{Biological activity}

The antimicrobial activity was determined in vitro by broad-dilution method against strains of S. aureus (ATCC25923), E. coli (C 600) and C. albicans (SC5314) ${ }^{46}$.

The experimental data revealed that all of the tested 1,2,4-oxadiazoles exhibited low to medium activity against both Gram-positive and Gram-negative bacterial strains (Table 2).

Table 2. MIC values in $\mu \mathrm{g} / \mathrm{mL} \mu \mathrm{mol} / \mathrm{mL}$ for compounds $\mathbf{4 d - g}$ and $\mathbf{4 j - p}$ against various bacterial strains and fungi.

\begin{tabular}{cccccccc}
\hline & & \multicolumn{2}{c}{ Gram-negative } & \multicolumn{2}{c}{ Gram-positive } & \multicolumn{2}{c}{ Fungi } \\
\cline { 3 - 8 } Entry & \multirow{2}{*}{ Compound } & \multicolumn{2}{c}{ E. coli } & \multicolumn{2}{c}{ S. aureus } & \multicolumn{2}{c}{ C. albicans } \\
\cline { 3 - 8 } & & MIC, & MIC, & MIC, & MIC, & MIC, & MIC, \\
& & $\mu \mathrm{g} / \mathrm{mL}$ & $\mathrm{mM}$ & $\mu \mathrm{g} / \mathrm{mL}$ & $\mathrm{mM}$ & $\mu \mathrm{mL}$ & $\mathrm{mM}$ \\
\hline 1 & $\mathbf{4 d}$ & 215 & 1,07 & 215 & 1,07 & 146 & 0,73 \\
2 & $\mathbf{4 e}$ & 267 & 1,07 & 213 & 0,86 & $>181$ & $>0,73$ \\
3 & $\mathbf{4 f}$ & 304 & 1,07 & 304 & 1,07 & $>207$ & $>0,73$ \\
4 & $\mathbf{4 g}$ & 299 & 1,07 & 299 & 1,07 & $>203$ & $>0,73$ \\
5 & $\mathbf{4 i}$ & 331 & 1,07 & 331 & 1,07 & $>225$ & $>0,73$ \\
6 & $\mathbf{4 j}$ & 331 & 1,07 & 331 & 1,07 & 225 & 0,73 \\
7 & $\mathbf{4 k}$ & 288 & 1,07 & 288 & 1,07 & $>196$ & $>0,73$ \\
8 & $\mathbf{4 l}$ & $>584$ & $>2,14$ & $>584$ & $>2,14$ & $>199$ & $>0,73$ \\
9 & $\mathbf{4 m}$ & 288 & 1,07 & 288 & 1,07 & $>196$ & $>0,73$ \\
10 & $\mathbf{4 n}$ & $>533$ & $>2,14$ & $>533$ & $>2,14$ & $>182$ & $>0,73$ \\
11 & $\mathbf{4 0}$ & 267 & 1,07 & 267 & 1,07 & $>181$ & $>0,73$ \\
12 & $\mathbf{4 p}$ & 304 & 1,07 & 304 & 1,07 & $>207$ & $>0,73$ \\
13 & Pefloxacin & 0,147 & 0,0003 & 148 & 0,003 & - & - \\
14 & Fluconazole & - & - & - & - & 149 & 0,0032 \\
\hline
\end{tabular}

The screening set included twelve compounds (4d-g and $\mathbf{4 i - p})$. Three synthesized 1,2,4-oxadiazoles (4a-4c) were too unstable at assay conditions, while $\mathbf{4 h}$ was insoluble in the assay medium. Therefore these compounds were excluded from the study. Pefloxacin and Fluconazole were used as reference standards for the comparison of antimicrobial activity. The minimum inhibitory concentration (MIC) for all compounds was determined. The experimental data (Table 2 ) revealed that all tested 1,2,4-oxadiazoles exhibit low to medium activity against both Gram- positive and Gram-negative bacterial strains.

The most active 1,2,4-oxadiazole 4e showed bacteriostatic effect with MIC $0.86 \mathrm{mM}(213 \mu \mathrm{g} / \mathrm{ml})$ against Staphylococcus aureus (ATCC-25923) and bacteriostatic effect with MIC $1.07 \mathrm{mM}(267 \mu \mathrm{g} / \mathrm{ml})$ against Escherichia coli (C-600). Other 1,2,4-oxadiazoles showed moderate to weak MIC against all tested bacteria. While compound $\mathbf{4}$ l bearing a furan ring displayed no antimicrobial activity in all tests, thiophene derivative $\mathbf{4 k}$ demonstrated moderate activity. Two 1,2,4-oxadiazoles (4d and 4i) showed medium fungistatic effect inhibiting the growth of Candida albicans (NCTC 885-653) with MIC 0.73 mM (146-225 $\mu \mathrm{g} / \mathrm{ml}$ respectively), which is, however, less potent than the standard drug Fluconazole $(1 \mu \mathrm{g} / \mathrm{ml} \text { against Candida albicans })^{50}$.

Overnight cultures were grown at $37^{\circ} \mathrm{C}$ in Lysogeny broth (LB) and diluted to obtain an opacity equivalent to 0.5 on the McFarland scale. The compounds are weighed and dissolved in DMSO to give concentrations equal to $20.7 \mu \mathrm{mol} / \mathrm{mL}$. The pefloxacin and miconazole were used to antimicrobial standard. The 
concentration of $2.07 \mu \mathrm{mol} / \mathrm{mL}$ was used as the starting one, providing a final concentration equal to 0.03 $\mu \mathrm{mol} / \mathrm{mL}$. The tubes were incubated for $12 \mathrm{~h}$ at $37^{\circ} \mathrm{C}$. Growth inhibition detection was considered as positive results. It was verified that DMSO as completely inactive against the tested microorganisms in the less than 10 $\%$ concentrations. A series of tubes is prepared by mixing one part of each dilution of the compound with some parts of the LB, previously inoculated and incubated for $24 \mathrm{~h}$ at $37{ }^{\circ} \mathrm{C}$. All experiments were carried out in triplicate. The MIC was considered the lowest drug concentration for which there is no microbial growth.

The most active 1,2,4-oxadiazole (4e) showed bacteriostatic effect with MIC $0.86 \mathrm{mM}(213 \mu \mathrm{g} / \mathrm{ml})$ against Staphylococcus aureus (ATCC-25923), and bacteriostatic effect with MIC $1.07 \mathrm{mM}$ (267 $\mu \mathrm{g} / \mathrm{ml})$ against Escherichia coli (C-600). Other 1,2,4-oxadiazoles showed moderate to weak MIC against all tested bacteria. While compound $\mathbf{4} \mathbf{I}$ bearing a furan ring displayed no antimicrobial activity in all tests, thiophene derivative $\mathbf{4 k}$ demonstrated moderate activity. Two 1,2,4-oxadiazoles (4d and 4i) showed medium fungistatic effect

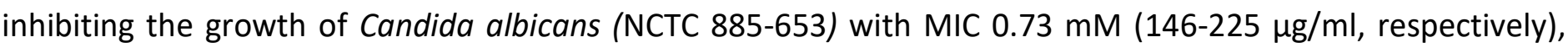
which is, however, less potent than the standard drug Fluconazole $(1 \mu \mathrm{g} / \mathrm{ml}$ against Candida albicans $) .{ }^{50}$

\section{Conclusions}

We have developed a simple, speedy and efficient method for the synthesis of 5-alkenyl- and 5-styryl-1,2,4oxadiazoles. A series of 16 compounds was obtained, 10 of which have not been previously reported in the literature. The novel synthetic protocol offers several advantages, including short reaction times, high yields of products, and simple work-up procedure. In addition, the twelve 1,2,4-oxadiazoles synthesized were evaluated agaist both Gram-positive and Gram-negative bacteria strains as well as one fungi strain, and displayed moderate antimicrobial activity.

\section{Experimental Section}

General. Starting $O$-acylamidoximes (3a-p) were synthesized from commercial nitriles in two steps (for more details see Supplemental Materials). All other reagents and solvents, including DMSO, were purchased and used without further purification. All reactions were conducted in an open flask.. Reactions were monitored by analytical thin layer chromatography (TLC) Macherey-Nagel, TLC plates Silufol UV-254 using UV light for detection. Column chromatography was carried out with silica gel grade 60 (0.040-0.063 mm) 230-400 mesh with a hexane/ethyl acetate mixture as eluent (4/1). NMR spectra were recorded on Bruker Avance DPX 400 (400.13 MHz and $100.61 \mathrm{MHz}$ for ${ }^{1} \mathrm{H}$ and ${ }^{13} \mathrm{C}$, respectively) or on Bruker Avance III $500 \mathrm{MHz}\left(500.03 \mathrm{MHz}\right.$ for ${ }^{1} \mathrm{H}$ and $125.73 \mathrm{MHz}$ for ${ }^{13} \mathrm{C}$ ) in DMSO- $d_{6}$ or in $\mathrm{CDCl}_{3}$. Chemical shifts are reported as parts per million $(\delta, \mathrm{ppm})$. The solvent peaks were used as internal standards: $2.50 \mathrm{ppm}$ for residual ${ }^{1} \mathrm{H}, 39.50 \mathrm{ppm}$ for ${ }^{13} \mathrm{C}$ in DMSO- $d_{6}$; 7.26 ppm for residual ${ }^{1} \mathrm{H}, 77.16$ ppm for ${ }^{13} \mathrm{C}$ in $\mathrm{CDCl}_{3}$. Multiplicities are abbreviated as follows: $s=$ singlet, $d=$ doublet, $t=$ triplet, $q=$ quartet, $m=$ multiplet, $b r=$ broad and coupling constants, $J$, are reported in Hertz $(\mathrm{Hz})$. The signals of second-order proton systems $A A^{\prime} X X^{\prime}$ of the para-substituted and $A A^{\prime} X X^{\prime} Y$ of the monosubstituted phenyl rings are not seen clearly in the ${ }^{1} \mathrm{H}$ NMR spectra, therefore, "apparent" coupling constants for observed "doublets" and "triplets" of appropriate aromatic protons are provided. Melting points were determined in open capillary tubes on Electrothermal IA 9300 series Digital Melting Point Apparatus. High-resolution mass spectra (HRMS) were measured on Bruker Maxis HRMS-ESI-qTOF (ESI Ionization). IR spectra were measured with an IRF Perkin Elmer Spectrum RX1 spectrometer using suspension in Nujol or as 
in thin films (microlayer) between $\mathrm{KBr}$ discs. Gel permeation chromatography was performed on DIONEX UltiMate-3000 (column: $I=15 \mathrm{~cm}, d=2 \mathrm{~mm}$ ). A mixture of acetonitrile and water (1:4) was used as eluent. "Th" is the abbreviation for the thiophen ring.

Synthesis and characterization of 1,2,4-oxadiazoles (4a-p). The corresponding $O$-acylamidoxime (3a-p) (1.5 $\mathrm{mmol}$ ) was added to a suspension of powdered $\mathrm{KOH}$ (1.5 or $0.15 \mathrm{mmol}$, see Table 1 ) in DMSO (2 mL). The reaction mixture was stirred at room temperature for a specified time (see Table 1). The reaction mixture was diluted with cold water $(20 \mathrm{~mL})$, and resulted precipitate was filtered off, washed with cold water $(25 \mathrm{~mL})$ and dried in air at room temperature.

3-Phenyl-5-vinyl-1,2,4-oxadiazole (4a). ${ }^{13}$ The compound was synthesized using 0.1 equiv of $\mathrm{KOH}$ for $0.5 \mathrm{~h}$. Yield after purification by column chromatography (ethyl acetate : hexane $1: 4$ ) was $11 \%$ (28 $\mathrm{mg}$ ) of yellow oil. IR (microlayer, vmax, cm ${ }^{-1}$ ): $1215(\mathrm{C}-\mathrm{O}), 1593(\mathrm{C}=\mathrm{N}), 1647\left(\mathrm{CH}=\mathrm{CH}_{2}\right) .{ }^{1} \mathrm{H}$ NMR $\left(400 \mathrm{MHz}, \mathrm{DMSO}-d_{6}\right): \delta_{\mathrm{H}} 6.08$ $\left(1 \mathrm{H}, \mathrm{d}, J 11 \mathrm{~Hz}, \mathrm{cis}-\mathrm{HC}=\underline{\mathrm{H}}_{2}\right), 6.53\left(1 \mathrm{H}, \mathrm{d}, J 18 \mathrm{~Hz}, \operatorname{tr}-\mathrm{HC}=\underline{\mathrm{C}}_{2}\right), 6.88(1 \mathrm{H}, \mathrm{dd}, J 18 \mathrm{~Hz}, 11 \mathrm{~Hz}, \underline{\mathrm{HC}}=\mathrm{C}), 7.48-7.55(3 \mathrm{H}$, $\mathrm{m}, \mathrm{m}, p-\mathrm{H}), 7.97-8.04(2 \mathrm{H}, \mathrm{m}, o-\mathrm{H}) .{ }^{13} \mathrm{C}$ NMR $\left(101 \mathrm{MHz}, \mathrm{DMSO}-d_{6}\right): \delta_{\mathrm{C}} 120.7\left(=\mathrm{CH}_{2}\right), 126.6(i-\mathrm{C}), 127.4(m-\mathrm{C})$, $129.5(o-C), 130.2(-\mathrm{CH}=), 131.9(p-\mathrm{C}), 168.4$ (C-3), 174.9 (C-5). HRMS (ESI), $m / z$ : calcd for $\mathrm{C}_{10} \mathrm{H}_{9} \mathrm{~N}_{2} \mathrm{O}[\mathrm{M}+\mathrm{H}]^{+}$ 173.0709 , found 173.0701.

3-Phenyl-5-(prop-1-en-2-yl)-1,2,4-oxadiazole (4b). The compound was synthesized using 0.1 equiv of $\mathrm{KOH}$ for $0.5 \mathrm{~h}$. Total yield after purification by column chromatography (ethyl acetate : hexane $1: 4)$ was $15 \%$ (41 mg) of yellow oil. IR (microlayer, vmax, $\left.\mathrm{cm}^{-1}\right)$ : $1158(\mathrm{C}-\mathrm{O}), 1578(\mathrm{C}=\mathrm{N}), 1643\left(\mathrm{CH}_{2}=\mathrm{C}\right) .{ }^{1} \mathrm{H}$ NMR (400 MHz, DMSO-d $\left.d_{6}\right)$ : $\delta_{\mathrm{H}} 2.22(3 \mathrm{H}, \mathrm{s}, \mathrm{Me}), 5.88\left(1 \mathrm{H}, \mathrm{s},=\mathrm{CH}_{2}\right), 6.28\left(1 \mathrm{H}, \mathrm{s},=\mathrm{CH}_{2}\right), 7.55-7.61(3 \mathrm{H}, \mathrm{m}, m, p-\mathrm{H}), 8.03(2 \mathrm{H}, \mathrm{d}, J 7.9 \mathrm{~Hz}, o-\mathrm{H})$. ${ }^{13} \mathrm{C}$ NMR $\left(101 \mathrm{MHz}, \mathrm{DMSO}-d_{6}\right): \delta_{\mathrm{C}} 18.9(\mathrm{Me}), 125.2\left(\mathrm{CH}_{2}=\right), 125.9(\mathrm{C}=), 126.7(\mathrm{i}-\mathrm{C}), 127.4(\mathrm{~m}-\mathrm{C}), 129.5(\mathrm{o}-\mathrm{C})$, $131.9(p-C), 168.5$ (C-3), 176.5 (C-5). HRMS (ESI), $m / z$ : calcd for $\mathrm{C}_{11} \mathrm{H}_{11} \mathrm{~N}_{2} \mathrm{O}[\mathrm{M}+\mathrm{H}]^{+}$187.0866, found 187.0860. (E)-3-Phenyl-5-(prop-1-en-1-yl)-1,2,4-oxadiazole (4c). ${ }^{17}$ The compound was synthesized using 0.1 equiv of $\mathrm{KOH}$ for $0.5 \mathrm{~h}$. Yield 79\% (220 mg); yellow oil. IR (microlayer, vmax, cm ${ }^{-1}$ ): 1120 (C-O), 1562 (C=N), 1665 $(\mathrm{CH}=\mathrm{CH}) .{ }^{1} \mathrm{H} N M R\left(500 \mathrm{MHz}, \mathrm{CDCl}_{3}\right): \delta_{\mathrm{H}} 2.05(3 \mathrm{H}, \mathrm{dd}, J$ 7.0, 2, Me), $6.50(1 \mathrm{H}, \mathrm{dq}, J 16.2,2 \mathrm{~Hz}, \mathrm{Het}-\mathrm{CH}=), 7.18$ $(1 \mathrm{H}, \mathrm{dq}, J 16.2,7.0 \mathrm{~Hz}, \mathrm{Me}-\mathrm{CH}=), 7.49-7.52(3 \mathrm{H}, \mathrm{m}, m, p-\mathrm{H}), 8.11(2 \mathrm{H}, \mathrm{d}, J 8.2 \mathrm{~Hz}, o-\mathrm{H}) .{ }^{13} \mathrm{C} \mathrm{NMR}(125 \mathrm{MHz}$, $\mathrm{CDCl}_{3}$ ): $\delta_{\mathrm{c}} 18.8$ (Me), 115.0 (Het-CH=), $127.0(i-\mathrm{C}), 127.4(m-\mathrm{C}), 128.8(o-\mathrm{C}), 131.0(p-\mathrm{C}), 142.8(\mathrm{Ph}-\mathrm{CH}=), 168.4$ (C-3), 174.7 (C-5). HRMS (ESI), $m / z$ : calcd for $\mathrm{C}_{11} \mathrm{H}_{11} \mathrm{~N}_{2} \mathrm{O}[\mathrm{M}+\mathrm{H}]^{+} 187.0866$, found 187.0853 .

5-(2-Methylprop-1-enyl)-3-phenyl-1,2,4-oxadiazole (4d). The compound was synthesized using 0.1 equiv of $\mathrm{KOH}$ for $0.5 \mathrm{~h}$. Yield $80 \%$ (240 mg); beige powder, mp 44-46 ${ }^{\circ} \mathrm{C} . \mathrm{IR}, \mathrm{v}, \mathrm{cm}^{-1}: 841$ (C=CH), 1152 (C-O), 1592 (C=N), 1656 (C=CH). ${ }^{1} \mathrm{H} \mathrm{NMR}\left(500 \mathrm{MHz}, \mathrm{CDCl}_{3}\right.$ ), $\delta 2.09$ (d, J 1.0 Hz, Me, 3H), 2.38 (d, J 1.0 Hz, Me, 3H), 6.33 (sept, J 1.2 $\mathrm{Hz}, \mathrm{C}=\mathrm{CH}, 1 \mathrm{H}), 7.49-7.52(\mathrm{~m}, \mathrm{~m}, \mathrm{p}-\mathrm{H}, 3 \mathrm{H}), 8.14(\mathrm{~m}, \mathrm{o}-\mathrm{H}, 2 \mathrm{H}) .{ }^{13} \mathrm{C} \mathrm{NMR}\left(125 \mathrm{MHz}, \mathrm{CDCl}_{3}\right), \delta 21.1(\mathrm{Me}), 27.6(\mathrm{Me})$, $108.9(\mathrm{C}=\underline{\mathrm{CH}}), 127.3(\mathrm{i}-\mathrm{C}), 127.4(\mathrm{~m}-\mathrm{C}), 128.8(o-\mathrm{C}), 130.9(p-\mathrm{C}), 154.3(\underline{\mathrm{C}}=\mathrm{CH}), 168.1(\mathrm{C}-3), 175.1$ (C-5). HRMS (ESI), $m / z$ : calcd for $\mathrm{C}_{12} \mathrm{H}_{13} \mathrm{~N}_{2} \mathrm{O}[\mathrm{M}+\mathrm{H}]^{+} 201.1022$, found 201.1020 .

(E)-3-Phenyl-5-(2-phenylethenyl)-1,2,4-oxadiazole (4e). ${ }^{19}$ Yield 87\% (324 mg), white powder, mp 95-97 ${ }^{\circ} \mathrm{C}$ (Lit.

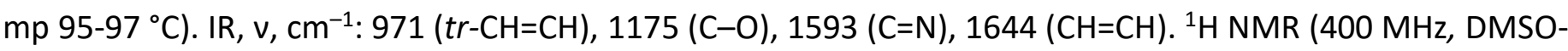
$\left.d_{6}\right): \delta_{H} 7.45(1 \mathrm{H}, \mathrm{d}, J 16.4 \mathrm{~Hz}$, Het- $\mathrm{CH}=), 7.43-7.49(3 \mathrm{H}, \mathrm{m}, m, p-\mathrm{H}), 7.56-7.63(3 \mathrm{H}, \mathrm{m}, m, p-\mathrm{H}), 7.85(2 \mathrm{H}, \mathrm{m}, o-\mathrm{H})$, $7.95(1 \mathrm{H}, \mathrm{d}, J 16.4 \mathrm{~Hz}, \mathrm{Ph}-\mathrm{CH}=)$, 8.05-8.09 (2H, m, o-H). ${ }^{13} \mathrm{C}$ NMR (101 MHz, DMSO-d $)$ ): $\delta_{\mathrm{c}} 110.7$ (Het-CH=), 126.8 (i-C, 3-Ph), 127.5 (o-C, 5- Ph), 128.9 (m-C, 3- Ph), 129.5 ( $p-C, 5-\mathrm{Ph}), 129.7$ (m-C, 5- Ph), 131.1 (o-C, 3- Ph), 132.0 (p-C, 3- Ph), 134.7 (i-C, 5-Ph), 143.3 (Ph-CH=), 168.5 (C-3), 175.9 (C-5). HRMS (ESI), $m / z$ : calcd for $\mathrm{C}_{16} \mathrm{H}_{13} \mathrm{~N}_{2} \mathrm{O}[\mathrm{M}+\mathrm{H}]^{+}$249.1022, found 249.1014.

5-[(E)-2-(4-Chlorophenyl)ethenyl]-3-phenyl-1,2,4-oxadiazole (4f). ${ }^{19}$ Yield 88\% (373 mg), white powder, mp 158-160 ${ }^{\circ} \mathrm{C}$ (Lit. mp 154-156 ${ }^{\circ} \mathrm{C}$ ). IR, v, cm ${ }^{-1}$ : 975 (tr-CH=CH), $1174(\mathrm{C}-\mathrm{O}), 1573(\mathrm{C}=\mathrm{N}), 1648(\mathrm{CH}=\mathrm{CH}) .{ }^{1} \mathrm{H} N M R$ (400 MHz, DMSO- $\left.d_{6}\right): \delta_{\mathrm{H}} 7.50(1 \mathrm{H}, \mathrm{d}, J 16.5$, Het-HC=), $7.55(2 \mathrm{H}, \mathrm{d}, J 8.5 \mathrm{~Hz}, m-\mathrm{H}), 7.58-7.63(3 \mathrm{H}, \mathrm{m}, m, p-\mathrm{H})$, 
$7.90(2 \mathrm{H}, \mathrm{d}, J 8.5 \mathrm{~Hz}, o-\mathrm{H}), 7.96(1 \mathrm{H}, \mathrm{d}, J 16.5 \mathrm{~Hz}, \mathrm{Ph}-\mathrm{HC}=), 8.05-8.08(2 \mathrm{H}, \mathrm{m}, o-\mathrm{H}) .{ }^{13} \mathrm{C}$ NMR (101 MHz, DMSO$\left.d_{6}\right): \delta_{c} 111.5$ (Het-CH=), 126.7 (i-C, 3-Ph), 127.5 (m-C, 3-Ph), 129.5 (o-C, 3-Ph), 129.7 (m-C, 5-Ph), 130.6 (o-C, 5$\mathrm{Ph}), 132.1$ (p-C, 3-Ph), 133.7 (i-C, 5-Ph), 135.7 (p-C, 5-Ph), 141.9 (Ph-CH=), 168.5 (C-3), 175.7 (C-5). HRMS (ESI), $\mathrm{m} / \mathrm{z}$ : calcd for $\mathrm{C}_{16} \mathrm{H}_{12} \mathrm{ClN}_{2} \mathrm{O}[\mathrm{M}+\mathrm{H}]^{+} 283.0633$, found 283.0632 .

3-(4-Methoxyphenyl)-5-[(E)-2-phenylethenyl]-1,2,4-oxadiazole (4g). ${ }^{19}$ Yield 80\% (333 mg), white powder, $\mathrm{mp}$ 122-123 ${ }^{\circ} \mathrm{C}$ (Lit. mp 130-132 ${ }^{\circ} \mathrm{C}$ ). IR, v, cm ${ }^{-1}: 975$ (tr-CH=CH), 1177, 1255 (C-O), 1556 (C=N), 1637 (CH=CH). ${ }^{1} \mathrm{H}$ NMR (400 MHz, DMSO-d $)$ : $\delta_{H} 3.85(3 \mathrm{H}, \mathrm{s}, \mathrm{OMe}), 7.14(2 \mathrm{H}, \mathrm{d}, J 8.9 \mathrm{~Hz}, m-\mathrm{H}), 7.43(1 \mathrm{H}, \mathrm{d}, J 16.5 \mathrm{~Hz}, \mathrm{Het}-\mathrm{CH}=)$, 7.46-7.50 (3H, m, m, p-H), 7.85-7.87 (2H, m, o-H), $7.94(1 \mathrm{H}, \mathrm{d}, J 16.5 \mathrm{~Hz}, \mathrm{Ph}-\mathrm{CH}=), 8.00(2 \mathrm{H}, \mathrm{d}, J 8.8 \mathrm{~Hz}, o-\mathrm{H}) .{ }^{13} \mathrm{C}$ NMR (101 MHz, DMSO- $d_{6}$ ): $\delta_{c} 55.9$ (OMe), 110.8 (Het-CH=), 115.1 (m-C, 3-Ph), 119.1 (i-C, 3-Ph), 128.8 (o-C, 5$\mathrm{Ph}), 129.2$ (o-C, 3-Ph), 129.5 ( $m-\mathrm{C}, 5-\mathrm{Ph}), 131.1$ (p-C, 5-Ph), 134.8 (i-C, 5-Ph), 143.1 (Ph-CH=), 162.2 ( $p-\mathrm{C}, 3-\mathrm{Ph})$, 168.2 (C-3), 175.6 (C-5). HRMS (ESI), $m / z$ : calcd for $\mathrm{C}_{17} \mathrm{H}_{15} \mathrm{~N}_{2} \mathrm{O}_{2}[\mathrm{M}+\mathrm{H}]^{+} 279.1128$, found 279.1133.

3-(4-Methoxyphenyl)-5-[(E)-2-(4-methoxyphenyl) ethenyl]-1,2,4-oxadiazole (4h). ${ }^{19}$ Yield 82\% (379 mg), white

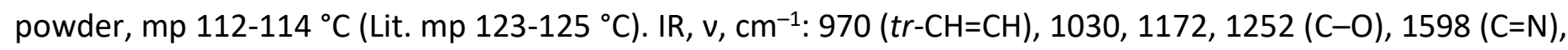
$1642(\mathrm{CH}=\mathrm{CH}) .{ }^{1} \mathrm{H} N M R\left(400 \mathrm{MHz}, \mathrm{DMSO}-d_{6}\right): \delta_{\mathrm{H}} 3.83(6 \mathrm{H}, \mathrm{d}, J 8.2 \mathrm{~Hz}, \mathrm{OMe}), 7.03(2 \mathrm{H}, \mathrm{d}, J 8.5 \mathrm{~Hz}, m-\mathrm{H}, 5-\mathrm{Ph})$, $7.12(2 \mathrm{H}, \mathrm{d}, J 8.9 \mathrm{~Hz}, m-\mathrm{H}, 3-\mathrm{Ph}), 7.24(1 \mathrm{H}, \mathrm{d}, J 16.4 \mathrm{~Hz}, \mathrm{Het}-\mathrm{CH}=), 7.80(2 \mathrm{H}, \mathrm{d}, J 8.8 \mathrm{~Hz}, o-\mathrm{H}, 5-\mathrm{Ph}), 7.86(1 \mathrm{H}, \mathrm{d}, J$ $16.4 \mathrm{~Hz}, \mathrm{Ph}-\mathrm{CH}=), 7.98(2 \mathrm{H}, \mathrm{d}, J 8.8 \mathrm{~Hz}, o-\mathrm{H}, 3-\mathrm{Ph}) .{ }^{13} \mathrm{C}$ NMR (101 MHz, DMSO-d 6 ): $\delta \mathrm{c} 55.9$ (2 OMe), 108.1 (Het$\mathrm{CH}=$ ), 115.0 (m-C, 3-Ph), 115.1 (m-C, 5-Ph), 119.2 (i-C, 3-Ph), 127.4 (i-C, 5-Ph), 129.1 (o-C, 3-Ph), 130.6 (o-C, 5$\mathrm{Ph}), 142.9$ (Ph-CH=), 161.8 (p-C, 5-Ph), 162.1 (p-C, 3-Ph), 168.1 (C-3), 175.9 (C-5). HRMS (ESI), m/z: calcd for $\mathrm{C}_{18} \mathrm{H}_{17} \mathrm{~N}_{2} \mathrm{O}_{3}[\mathrm{M}+\mathrm{H}]^{+}$309.1234, found 309.1231.

5-[(E)-2-(3,4-Dimethoxyphenyl)ethenyl]-3-phenyl-1,2,4-oxadiazole (4i). Yield 80\% (369 mg), white powder, $\mathrm{mp} 118-119^{\circ} \mathrm{C} . \mathrm{IR}, \mathrm{v}, \mathrm{cm}^{-1}$ : 966 (tr-CH=CH), 1039, 1266 (C-O), $1582(\mathrm{C}=\mathrm{N}), 1646(\mathrm{CH}=\mathrm{CH}) .{ }^{1} \mathrm{H} \mathrm{NMR}(400 \mathrm{MHz}$, DMSO- $\left.d_{6}\right): \delta_{H} 3.82(3 \mathrm{H}, \mathrm{s}, \mathrm{OMe}), 3.86(3 \mathrm{H}, \mathrm{s}, \mathrm{OMe}), 7.03(1 \mathrm{H}, \mathrm{d}, \mathrm{J} 8.2 \mathrm{~Hz}, \mathrm{H}-6,5-\mathrm{Ph}), 7.35$ (1H, d, J 8.2 Hz, H-5, 5$\mathrm{Ph}), 7.36(1 \mathrm{H}, \mathrm{d}, J 16.5 \mathrm{~Hz}, \mathrm{Ar}-\mathrm{CH}=), 7.51(1 \mathrm{H}, \mathrm{s}, \mathrm{H}-2,5-\mathrm{Ph}), 7.60(3 \mathrm{H}, \mathrm{m}, m, p-\mathrm{H}, \mathrm{Ph}), 7.87(1 \mathrm{H}, \mathrm{d}, J 16.5 \mathrm{~Hz}, \mathrm{Ph}-$ $\mathrm{CH}=), 8.06(2 \mathrm{H}, \mathrm{m}, o-\mathrm{H}, \mathrm{Ph}) .{ }^{13} \mathrm{C}$ NMR (101 MHz, DMSO- $\left.d_{6}\right): \delta_{\mathrm{C}} 56.1$ (OMe), 56.2 (OMe), 108.2 (Het-CH=), 110.8 ( $\mathrm{CH}, \mathrm{Ar}), 112.1$ ( $\mathrm{CH}, \mathrm{Ar}), 123.7$ (CH, Ar), 126.9 (i-C, Ph), 127.5 (m-C, Ph), 127.6 (i-C, Ar), 129.7 (o-C, Ph), 131.9 (pC, Ph), 143.5 (Ar-CH=), 149.6 (C, Ar), 151.7 (C, Ar), 168.4 (C-3), 176.3 (C-5). HRMS (ESI) calcd for $\mathrm{C}_{18} \mathrm{H}_{17} \mathrm{~N}_{2} \mathrm{O}_{3}$ $[\mathrm{M}+\mathrm{H}]^{+} 309.1234$, found 309.1238 .

5-[(E)-2-(2,3-Dimethoxyphenyl)ethenyl]-3-phenyl-1,2,4-oxadiazole (4j). Yield 79\% (365 mg), white powder,

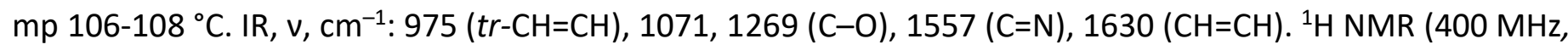
DMSO- $\left.d_{6}\right): \delta_{H} 3.85(6 \mathrm{H}, \mathrm{s}, 2 \mathrm{Me}), 7.17(2 \mathrm{H}, \mathrm{m}, \mathrm{H}-4,6, \mathrm{Ar}), 7.41(1 \mathrm{H}, \mathrm{d}, J 16.5 \mathrm{~Hz}$, Het-CH=), $7.51(1 \mathrm{H}, \mathrm{m}, \mathrm{H}-5, \mathrm{Ar})$, 7.55-7.63 (3H, m, $m, p-\mathrm{H}), 8.05-8.10(3 \mathrm{H}, \mathrm{m}, o-\mathrm{H}, \mathrm{Ph}-\mathrm{CH}=) .{ }^{13} \mathrm{C}$ NMR (101 MHz, DMSO-d $)$ : $\delta_{\mathrm{C}} 56.3$ (OMe), 61.4 (OMe), 111.7 Het-CH=), $115.6(\mathrm{CH}, \mathrm{Ar}), 119.5(\mathrm{CH}, \mathrm{Ar}), 124.9(\mathrm{CH}, \mathrm{Ar}), 126.8(i-\mathrm{C}, \mathrm{Ph}), 127.5(m-\mathrm{C}, \mathrm{Ph}), 128.1(i-$ C, Ar), 129.7 (o-C, Ph), 132.0 (p-C, Ph), 137.4 (Ar-CH=), 148.3 (C, Ar), 153.2 (C, Ar), 168.5 (C-3), 176.0 (C-5). HRMS (ESI), $m / z$ : calcd for $\mathrm{C}_{18} \mathrm{H}_{17} \mathrm{~N}_{2} \mathrm{O}_{3}[\mathrm{M}+\mathrm{K}]^{+} 347.0793$, found 347.0794.

3-(4-Methylphenyl)-5-[(E)-2-(thiophen-2-yl)ethenyl]-1,2,4-oxadiazole (4k). Yield 85\% (342 mg), white powder, mp 102-104 ${ }^{\circ} \mathrm{C} . \mathrm{IR}, \mathrm{v}, \mathrm{cm}^{-1}$ : 954 (tr-CH=CH), 1160 (C-O), 1550 (C=N), $1629(\mathrm{CH}=\mathrm{CH}) .{ }^{1} \mathrm{H} \mathrm{NMR}(400 \mathrm{MHz}$, DMSO- $\left.d_{6}\right): \delta_{H} 2.35(3 \mathrm{H}, \mathrm{s}, \mathrm{Me}), 6.98(1 \mathrm{H}, \mathrm{d}, J 15.8 \mathrm{~Hz}, \mathrm{Het}-\mathrm{CH}=), 7.17(1 \mathrm{H}, \mathrm{dd}, J$ 5.0,3.3 Hz, Th, H-4), $7.33(2 \mathrm{H}, \mathrm{d}$, J $7.9 \mathrm{~Hz}, m-\mathrm{H}), 7.63(1 \mathrm{H}, \mathrm{d}, J 3.3 \mathrm{~Hz}, \mathrm{Th}, \mathrm{H}-3), 7.77(1 \mathrm{H}, \mathrm{d}, J 5.0 \mathrm{~Hz}, \mathrm{Th}, \mathrm{H}-5), 7.90(2 \mathrm{H}, \mathrm{d}, J 7.9 \mathrm{~Hz}, o-\mathrm{H}), 8.04(1 \mathrm{H}$, d, J $16.2 \mathrm{~Hz}$, Th-CH=). ${ }^{13} \mathrm{C}$ NMR (101 MHz, DMSO- $\left.d_{6}\right): \delta_{c} 21.5$ (Me), 108.7 (Het-CH=), 124.0 (Th, C-4), 127.4 (oC), 129.1 (Th, C-3), 130.1 (m-C), 130.8 (i-C, Ph), 132.5 (Th, C-5), 135.8 (Th, C-2), 139.5 ( $p-\mathrm{C}), 141.8$ (Het-CH=), 168.4 (C-3), 175.3 (C-5). HRMS (ESI), $m / z$ : calcd for $\mathrm{C}_{15} \mathrm{H}_{13} \mathrm{~N}_{2} \mathrm{OS}[\mathrm{M}+\mathrm{H}]^{+} 269.0743$, found 269.0751.

3-(4-Chlorophenyl)-5-[(E)-2-(furan-2-yl)ethenyl]-1,2,4-oxadiazole (4I). Yield 78\% (319 mg), white powder, mp 115-116 ${ }^{\circ} \mathrm{C} . \mathrm{IR}, \mathrm{v}, \mathrm{cm}^{-1}$ : 964 (tr-CH=CH), 1091, 1272 (C-O), 1528 (C=N), $1653(\mathrm{CH}=\mathrm{CH}) .{ }^{1} \mathrm{H}$ NMR $(400 \mathrm{MHz}$, DMSO- $\left.d_{6}\right): \delta_{H} 6.71(1 \mathrm{H}, \mathrm{dd}, J 3.4,1.8 \mathrm{~Hz}$, Fur, H-4), $6.97(1 \mathrm{H}, \mathrm{d}, J 15.9 \mathrm{~Hz}, \mathrm{Het}-\mathrm{CH}=), 7.09(1 \mathrm{H}, \mathrm{d}, J 3.4 \mathrm{~Hz}, \mathrm{Fur}, \mathrm{H}-$ 
3), $7.66(2 \mathrm{H}, \mathrm{d}, J 8.5 \mathrm{~Hz}, m-\mathrm{H}), 7.79(1 \mathrm{H}, \mathrm{d}, \mathrm{J} 16.2 \mathrm{~Hz}$, Fur-CH=), $7.95(1 \mathrm{H}, \mathrm{m}$, Fur, H-5), 8.05 (5H, d, J $8.5 \mathrm{~Hz}, \mathrm{o}-\mathrm{H})$. ${ }^{13} \mathrm{C}$ NMR (101 MHz, DMSO- $\left.d_{6}\right)$ : $\delta \mathrm{c} 107.0$ (Het-CH=), 113.6 (Fur, C-3), 117.2 (Fur, C-4), 125.6 (i-C, Ph), 129.3 (mC), 129.9 (o-C), 130.1 (Fur-CH=), 136.8 (p-C), 147.0 (Fur, C-5), 150.7 (Fur, C-2), 167.7 (C-3), 175.9 (C-5). HRMS (ESI), $m / z$ : calcd for $\mathrm{C}_{14} \mathrm{H}_{10} \mathrm{ClN}_{2} \mathrm{O}_{2}[\mathrm{M}+\mathrm{H}]^{+} 273.0425$, found 273.0427 .

3-(5-Methylthiophen-2-yl)-5-[(E)-2-phenylethenyl]-1,2,4-oxadiazole (4m). Yield 95\% (382 mg), white powder, $\mathrm{mp} 113-115^{\circ} \mathrm{C} . \mathrm{IR}, \mathrm{v}, \mathrm{cm}^{-1}$ : 974 (tr- $\left.\mathrm{CH}=\mathrm{CH}\right), 1098(\mathrm{C}-\mathrm{O}), 1572(\mathrm{C}=\mathrm{N}), 1643(\mathrm{CH}=\mathrm{CH}) .{ }^{1} \mathrm{H}$ NMR $(400 \mathrm{MHz}, \mathrm{DMSO}-$ $\left.d_{6}\right): \delta_{\mathrm{H}} 2.53(3 \mathrm{H}, \mathrm{s}, \mathrm{Me}), 6.98(1 \mathrm{H}, \mathrm{d}, J 3 \mathrm{~Hz}, \mathrm{H}-4, \mathrm{Th}), 7.41(1 \mathrm{H}, \mathrm{d}, J 16.4 \mathrm{~Hz}$, Het-HC=), 7.45-7.50 (3H, m, $m, p-\mathrm{H})$, $7.64\left(1 \mathrm{H}, \mathrm{d}, J 3.4 \mathrm{~Hz}, \mathrm{H}-3\right.$, Th), 7.84-7.87 (2H, m, o-H), $7.91(1 \mathrm{H}, \mathrm{d}, J 16.4 \mathrm{~Hz}, \mathrm{Ph}-\mathrm{HC}=) .{ }^{13} \mathrm{C} \mathrm{NMR}(101 \mathrm{MHz}$, DMSO- $d_{6}$ ): $\delta_{c} 15.6$ (Me), 110.5 (Het-CH=), 125.5 (Th, C-5), 127.5 (p-C), 128.9 (m-C), 129.5 (o-C), 130.5 (Th, C-3), 131.1 (Th, C-4), 134.7 (i-C), 143.4 (Ph-CH=), 145.0 (Th, C-2), 164.5 (C-3), 175.6 (C-5). HRMS (ESI), m/z: calcd for $\mathrm{C}_{15} \mathrm{H}_{13} \mathrm{~N}_{2} \mathrm{OS}[\mathrm{M}+\mathrm{H}]^{+}$269.0743, found 269.0748.

2-\{5-[(E)-2-Phenylethenyl]-1,2,4-oxadiazol-3-yl\}pyridine (4n). Yield 74\% (276 mg), white powder, mp 114-116 ${ }^{\circ} \mathrm{C} . \mathrm{IR}, \mathrm{v}, \mathrm{cm}^{-1}: 980$ (tr-CH=CH), 1071 (C-O), 1572 (C=N), $1644(\mathrm{CH}=\mathrm{CH}) .{ }^{1} \mathrm{H}$ NMR(400 MHz, DMSO-d $): \delta_{\mathrm{H}} 7.46-$ $7.50(4 \mathrm{H}, \mathrm{m}, m, p-\mathrm{H}, \mathrm{Ph}$, Het-CH=), $7.63(1 \mathrm{H}, \mathrm{ddd}, J$ 7.6, 4.9, $1.2 \mathrm{~Hz}, \mathrm{H}-5, \mathrm{Py}), 7.86-7.88(2 \mathrm{H}, \mathrm{m}, o-\mathrm{H}, \mathrm{Ph}), 7.99$ $(1 \mathrm{H}, \mathrm{d}, J 16.5 \mathrm{~Hz}, \mathrm{Ph}-\mathrm{CH}=), 8.05(1 \mathrm{H}, \mathrm{td}, J$ 7.7, $1.7 \mathrm{~Hz}, \mathrm{H}-4, \mathrm{Py}), 8.13(1 \mathrm{H}, \mathrm{d}, J 7.9 \mathrm{~Hz}, \mathrm{H}-3, \mathrm{Py}), 8.78(1 \mathrm{H}, \mathrm{d}, J 4.5$ $\mathrm{Hz}, \mathrm{H}-6, \mathrm{Py}) .{ }^{13} \mathrm{C}$ NMR (101 MHz, DMSO-d $): \delta_{\mathrm{c}} 110.7$ (Het-CH=), 123.8 (Py, C-3), 126.6 (Py, C-5), 128.9 (o-C), 129.5 ( $m-\mathrm{C}), 131.3$ (p-C), 134.7 (i-C, Ph), 138.2 (Ph-CH=), 143.6 (Py, C-4), 146.3 (Py, C-2), 150.8 (Py, C-6), 168.6 (C-3), 176.2 (C-5). HRMS (ESI), $m / z$ : calcd for $\mathrm{C}_{15} \mathrm{H}_{12} \mathrm{~N}_{3} \mathrm{O}[\mathrm{M}+\mathrm{H}]^{+} 250.0974$, found 250.0979 .

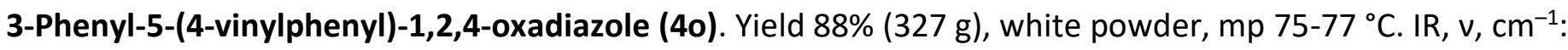
$991\left(\mathrm{CH}=\mathrm{CH}_{2}\right), 1276(\mathrm{C}-\mathrm{O}), 1594(\mathrm{C}=\mathrm{N}), 1627(\mathrm{CH}=\mathrm{CH}) .{ }^{1} \mathrm{H}$ NMR $\left(400 \mathrm{MHz}, \mathrm{DMSO}-d_{6}\right): \delta_{\mathrm{H}} 5.47(1 \mathrm{H}, \mathrm{d}, J 10.9 \mathrm{~Hz}$, cis- $\left.\mathrm{CH}=\underline{\mathrm{CH}}_{2}\right), 6.05\left(1 \mathrm{H}, \mathrm{d}, J 17.5 \mathrm{~Hz}, \operatorname{tr}-\mathrm{CH}=\underline{\mathrm{C}}_{2}\right), 6.86\left(1 \mathrm{H}, \mathrm{dd}, J 17.5,10.9 \mathrm{~Hz}, \underline{\mathrm{C}}=\mathrm{CH}_{2}\right), 7.60(3 \mathrm{H}, \mathrm{m}, m, p-\mathrm{H}, \mathrm{Ph})$, $7.74(2 \mathrm{H}, \mathrm{d}, \mathrm{J} 7.9 \mathrm{~Hz}, \mathrm{Ar}), 8.08-8.15(4 \mathrm{H}, \mathrm{m}, \mathrm{o}-\mathrm{H}, \mathrm{Ph}, \mathrm{Ar}) .{ }^{13} \mathrm{C}$ NMR (101 MHz, DMSO-d $)$ : $\delta_{c} 118.1\left(=\mathrm{CH}_{2}\right), 122.9$ $(i-C), 126.7(p-C), 127.6(o-C), 128.7(m-C), 129.7(m-C), 132.1(i-C), 136.1(-\mathrm{CH}=), 142.2(p-C), 168.7(\mathrm{C}-3), 175.6$ (C-5). HRMS (ESI), $m / z$ : calcd for $\mathrm{C}_{16} \mathrm{H}_{13} \mathrm{~N}_{2} \mathrm{O}[\mathrm{M}+\mathrm{H}]^{+} 249.1022$, found 249.1018 .

3-(4-Chlorophenyl)-5-(4-ethenylphenyl)-1,2,4-oxadiazole (4p). Yield 85\% (360 mg), white powder, mp 110$112{ }^{\circ} \mathrm{C} . \mathrm{IR}, \mathrm{v}, \mathrm{cm}^{-1}: 992\left(\mathrm{CH}=\mathrm{CH}_{2}\right), 1278(\mathrm{C}-\mathrm{O}), 1589$ (C=N), $1629(\mathrm{CH}=\mathrm{CH}) .{ }^{1} \mathrm{H}$ NMR (400 MHz, DMSO-d $): \delta_{H} 5.46$ $\left(1 \mathrm{H}, \mathrm{d}, J 10.9 \mathrm{~Hz}\right.$, cis- $\left.\mathrm{CH}=\underline{\mathrm{C}}_{2}\right), 6.00\left(1 \mathrm{H}, \mathrm{d}, J 17.5 \mathrm{~Hz}, \operatorname{tr}-\mathrm{CH}=\mathrm{CH}_{2}\right), 6.86\left(1 \mathrm{H}, \mathrm{dd}, J 17.5,10.9 \mathrm{~Hz}, \mathrm{CH}_{\mathbf{H}}=\mathrm{CH}_{2}\right), 7.58-$ $7.72(4 \mathrm{H}, \mathrm{m}), 8.01-8.14(4 \mathrm{H}, \mathrm{m}) .{ }^{13} \mathrm{C}$ NMR $\left(101 \mathrm{MHz}, \mathrm{DMSO}-d_{6}\right): \delta_{\mathrm{c}} 117.9\left(=\mathrm{CH}_{2}\right), 126.2(i-\mathrm{C}), 127.2(p-\mathrm{C}), 127.5$ (o-C), $128.7(m-\mathrm{C}), 131.5(m-\mathrm{C}), 131.8(i-\mathrm{C}), 134.5(-\mathrm{CH}=), 136.2(p-\mathrm{C}), 142.5(p-\mathrm{C}), 167.8$ (C-3), 176.0 (C-5). HRMS (ESI), $m / z$ : calcd for $\mathrm{C}_{16} \mathrm{H}_{12} \mathrm{CIN}_{2} \mathrm{O}[\mathrm{M}+\mathrm{H}]^{+} 283.0633$, found 283.0622 .

\section{Antimicrobial assay}

Overnight cultures were grown at $37^{\circ} \mathrm{C}$ in Lysogeny broth (LB) and diluted to obtain an opacity equivalent to 0.5 on the McFarland scale. The compounds are weighed and dissolved in DMSO to give concentrations equal to $21.4 \mu \mathrm{mol} / \mathrm{mL}$. The pefloxacin and fluconazole were used as to antimicrobial drug standards. The concentration of $2.14 \mu \mathrm{mol} / \mathrm{mL}$ was used as the starting one, providing a final concentration equal to 0.03 $\mu \mathrm{mol} / \mathrm{mL}$. The tubes were incubated for $12 \mathrm{~h}$ at $37^{\circ} \mathrm{C}$. Growth inhibition detection was considered as positive results. It was verified that DMSO as completely inactive against the tested microorganisms in the less than 0.5 $\%$ concentrations. A series of tubes is prepared by mixing one part of each dilution of the compound with some parts of the LB, previously inoculated and incubated for $24 \mathrm{~h}$ at $37^{\circ} \mathrm{C}$. All experiments were carried out in triplicate. Minimum inhibitory concentration (MIC) is the lowest concentration of an antimicrobial agent which will inhibit the visible growth of a micro-organism after overnight incubation. 


\section{Acknowledgements}

We thank Saint Petersburg State University for financial support (grant 12.37.214.2016). The antimicrobial evaluation of synthesized 1,2,4-oxadiazoles was financially supported by the Russian Foundation for Basic Research (RFBR) grant 18-33-01108.

We gratefully acknowledge Research Centre for Magnetic Resonance and Center for Chemical Analysis and Materials Research of Saint Petersburg State University for NMR and HR-Mass spectra of novel compounds.

The authors thank Dr. Alexey Fedorov (ETH Zurich) for his help in the preparation of this manuscript.

\section{Supplementary Material}

Supplementary material, including physical constants and spectral data for known compounds $(\mathbf{4 a}, \mathbf{4 c}, \mathbf{4 e}, \mathbf{4 f -}$ h), and copies of ${ }^{1} \mathrm{H}$ and ${ }^{13} \mathrm{C}$ NMR spectra for new compounds $4 \mathbf{b}, \mathbf{4 d}, \mathbf{4 i - p}$ can be accessed using the link "Supplementary Material" in the journal issue contents page.

\section{References}

1. Pace, A.; Pierro, P. Org. Biomol. Chem. 2009, 7, 4337-4348.

http://dx.doi.org/10.1039/B908937C

2. Khan, I.; Ibrar, A.; Abbas, N. Arch. Pharm. Chem. Life Sci. 2013, 346, 1-20. https://doi.org/10.1002/ardp.201300231

3. Pace, A.; Buscemi, S.; Piccionello, A. P.; Pibiri, I. Adv. Heterocycl. Chem. 2015, 116, 85-136. http://dx.doi.org/10.1016/bs.aihch.2015.05.001

4. Vaidya, A.; Jain, S.; Jain, P.; Jain, P.; Tiwari, N.; Jain, R.; Jain, R.; Jain, A. K.; Agrawal, R. K. Mini Rev. Med. Chem. 2016, 16, 825-845.

https://doi.org/10.2174/1389557516666160211120835

5. Olesen, P. H.; Tønder, J. E.; Hansen, J. B.; Hansen, H. C.; Rimvall, K. Bioorg. Med. Chem. 2000, 8, 14431450.

https://doi.org/10.1016/S0968-0896(00)00063-8

6. Macdonald, D.; Mastracchio, A.; Perrier, H.; Dubé, D.; Gallant, M.; Lacombe, P.; Deschênes, D.; Roy, B.; Scheigetz, J.; Bateman, K.; Li, C.; Trimble, L. A. Bioorg. Med. Chem. Lett. 2005, 15, 5241-5246.

https://doi.org/10.1016/i.bmcl.2005.08.036

7. Conlon, D. A.; Drahus-Paone, A.; Ho, G.-J.; Pipik, B.; Helmy, R.; McNamara, J. M.; Shi, Y.-J.; Williams, J. M.; Macdonald, D.; Deschênes, D.; Gallant, M.; Mastracchio, A.; Roy, B.; Scheigetz. J. Org. Process Res. Dev. 2006, 10, 36-45.

https://doi.org/10.1021/op0501161

8. Parikh, N.; Chakraborti, A. Curr. Med. Chem. 2016, 23(2), 129-141.

9. Benmansour, F.; Eydoux, C.; Querat, G.; de Lamballerie, X.; Canard, B.; Alvarez, K.; Guillemot, J.-C.; Barral, K. Eur. J. Med. Chem. 2016, 109(15), 146-156. http://dx.doi.org/10.1016/j.ejmech.2015.12.046 
10. Kaur, G.; Singh, K.; Pavadai, E.; Njoroge, M.; Espinoza-Moraga, M.; De Kock, C.; Smith, P. J.; Wittlin, S.; Chibale, K. Med. Chem. Commun. 2015, 6, 2023-2029.

http://dx.doi.org/10.1039/C5MD00343A

11. Nandeesh, K. N.; Swarup, H. A.; Sandhya, N. C.; Mohan, C. D.; Kumar, P. C. S.; Kumara, M. N.; Mantelingu, K.; Ananda, S.; Rangappa, K. S. New J. Chem. 2016, 40, 2823-2831.

http://dx.doi.org/10.1039/C5NJ02925B

12. Macor, J. E.; Ordway, T.; Smith, R. L.; Verhoest, P. R.; Mack, R. A. J. Org. Chem. 1996, 61, 3228-3229. https://doi.org/10.1021/jo9603340

13. Burns, A. R.; Kerr, J. H.; Kerr, W. J.; Passmore, J.; Paterson, L. C.; Watson, A. J. B. Org. Biomol. Chem. 2010, 8, 2777-2783.

http://dx.doi.org/10.1039/C001772H

14. Beletskii, E. V.; Ignatenko, O. A.; Kuznetsov, M. A.; Selivanov, S. I. Russ. J. Org. Chem. 2010, 46(5), 678-684. http://dx.doi.org/10.1134/S1070428010050143

15. Bakulev, V. A.; Efimov, I. V.; Belyaev, N. A.; Zhidovinov, S. S.; Rozin, Y. A.; Volkova, N. N.; Khabarova, A. A.; El'tsov, O. S. Chem. Heterocycl. Compd. 2013, 48, 1880-1882.

https://doi.org/10.1007/s10593-013-1225-1

16. Efimov, I.; Bakulev, V.; Beliaev, N.; Beryozkina, T.; Knippschild, U.; Leban, J.; Zhi-Jin, F.; Eltsov, O.; Slepukhin, P.; Ezhikova, M.; Dehaen, W. European J. Org. Chem. 2014, 17, 3684.

https://doi.org/10.1002/ejoc.201402130

17. Pattison, G.; Piraux, G.; Lam, H. W. J. Am. Chem. Soc. 2010, 132, 14373-14375.

https://doi.org/10.1021/ja106809p

18. Roy, I. D.; Burns, A. R.; Pattison, G.; Michel, B.; Parker, A. J.; Lam, H. W. Chem. Commun. 2014, 50, 28652868.

http://dx.doi.org/10.1039/C4CC00340C

19. Zalivatskaya, A. S.; Ryabukhin, D. S.; Tarasenko, M. V; Ivanov, A. Y.; Boyarskaya, I. A.; Grinenko, E. V; Osetrova, L. V.; Kofanov, E. R.; Vasilyev, A. V. Beilstein J. Org. Chem. 2017, 13, 883-894.

http://dx.doi.org/10.3762/bjoc.13.89

20. Tsiulin, P. A.; Sosnina, V. V.; Krasovskaya, G. G.; Danilova, A. S.; Baikov, S. V.; Kofanov, E. R. Russ. J. Org. Chem. 2011, 47, 1874-1877.

https://doi.org/10.1134/S1070428011120153

21. Augustine, J. K.; Akabote, V.; Hegde, S. G.; Alagarsamy, P. J. Org. Chem. 2009, 74(15), 5640-5643. https://doi.org/10.1016/i.tet.2009.09.114

22. Adib, M.; Saeedi, S.; Soheilizad, M.; Bayanati, M.; Tajbakhsh, M.; Amanlou, M J. Chem. Res. 2016, 40(5), 314-317.

23. Cheawchan, S.; Koyama, Y.; Uchida, S.; Takata, T. Polymer 2013, 54, 4501-4510.

http://dx.doi.org/10.1016/i.polymer.2013.06.020

24. Porcheddu, A.; Cadoni, R.; de Luca, L. Org. Biomol. Chem. 2011, 9, 7539-7546.

http://dx.doi.org/10.1039/C10B06055D

25. Baykov, S. V.; Zharov, A. A.; Stashina, G. A.; Zavarzin, I. V.; Kofanov, E. R. Mend. Commun. 2016, 26, 264265.

https://doi.org/10.1016/i.mencom.2016.05.015

26. Bora, R. O.; Farooqui, M. J. Heterocycl. Chem. 2007, 44(3), 645-649.

https://doi.org/10.1002/ihet.5570440321 
27. Kumar, D.; Patel, G.; Vijayakrishnan, L.; Dastidar, S. G.; Ray, A. Chem. Biol. Drug Des. 2012, 79, 810-818. https://doi.org/10.1111/j.1747-0285.2011.01304.x

28. Schenkel, L. B.; Olivieri, P. R.; Boezio, A. A.; Deak, H. L.; Emkey, R.; Graceffa, R. F.; Gunaydin, H.; GuzmanPerez, A.; Lee, J. H.; Teffera, Y.; Wang, W.; Youngblood, B. D.; Yu, V. L.; Zhang, M.; Gavva, N. R.; Lehto, S. G.; Geuns-Meyer, S. J. Med. Chem. 2016, 59(6), 2794-2809.

https://doi.org/10.1021/acs.jmedchem.6b00039

29. Benltifa, M.; Vidal, S.; Fenet, B.; Msaddek, M.; Goekjian, P. G.; Praly, J. P.; Brunyánszki, A.; Docsa, T.; Gergely, P. Eur. J. Org. Chem. 2006, 18, 4242-4256.

https://doi.org/10.1002/ejoc.200600073

30. Koufaki, M.; Theodorou, E.; Alexi, X.; Alexis, M. N. Bioorg. Med. Chem. 2010, 18, 3898-3909. https://doi.org/10.1016/i.bmc.2010.04.042

31. Gangloff, A. R.; Litvak, J.; Shelton, E. J.; Sperandio, D.; Wang, V. R.; Rice, K. D. Tetrahedron Lett. 2001, 42(8), 1441-1443.

https://doi.org/10.1016/S0040-4039(00)02288-7

32. Otaka, H.; Ikeda, J.; Tanaka, D.; Tobe, M. Tetrahedron Lett. 2014, 55(5), 979-981.

https://doi.org/10.1016/i.tetlet.2013.12.016

33. Guo, W.; Huang, K.; Ji, F.; Wu, W.; Jiang, H. Chem. Commun. 2015, 51, 8857-8860.

http://dx.doi.org/10.1039/C5CC02110C

34. Baykov, S.; Sharonova, T.; Osipyan, A.; Rozhkov, S.; Shetnev, A.; Smirnov, A. Tetrahedron Lett. 2016, 57(26), 2898-2900.

https://doi.org/10.1016/j.tetlet.2016.05.071

35. Baykov, S.; Sharonova, T.; Shetnev, A.; Rozhkov, S.; Kalinin, S.; Smirnov, A. V. Tetrahedron 2017, 73(7), 945-951.

https://doi.org/10.1016/i.tet.2017.01.007

36. Tarasenko, M.; Duderin, N.; Sharonova, T.; Baykov, S.; Shetnev, A.; Smirnov, A. V. Tetrahedron Lett. 2017, 58(37), 3672-3677.

https://doi.org/10.1016/i.tetlet.2017.08.020

37. Sharonova, T.; Pankrat'eva, V.; Savko, P.; Baykov, S.; Shetnev, A. Tetrahedron Lett. 2018, 59(29), 28242827.

https://doi.org/10.1016/i.tetlet.2018.06.019

38. The starting $O$-acylamidoximes 1 were obtained by the reaction of arylamidoximes with carboxylic acids in the presence of ethyl chloroformate (Neves Filho, R. A. W.; Bezerra, N. M. M.; Guedes, J. M.; Srivastava, R. M. J. Braz. Chem. Soc. 2009, 20(7), 1365-1369) or 1-ethyl-3-(3-dimethylaminopropyl)carbodiimide (Benltifa, M.; Vidal, S.; Fenet, B.; Msaddek, M.; Goekjian, P. G.; Praly, J.-P.; Brunyánszki, A.; Docsa, T.; Gergely, P. Eur. J. Org. Chem. 2006, 2006, 4242-4256). For more details, see Supplementary Data.

39. Maréchal, J.-M.; Carlotti, S.; Shcheglova, L.; Deffieux, A. Polymer 2003, 44, 7601-7607. https://doi.org/10.1016/i.polymer.2003.09.051

40. Molau, G. E.; Mason, J. E. J. Polym. Sci. Polym. Chem. 1966, 4, 2336. https://doi.org/10.1002/pol.1966.150040930

41. Maftei, C.-V.; Fodor, E.; Mangalagiu, I.; Jones, P. G.; Daniliuc, C.-G.; Franz, M. H.; Neda, I. Rev. Roum. Chim. 2010, 55, 989-994.

42. Wagenen, B.; Stormann, T.; Moe, S.; Sheehan, S.; Mcleod, D.; Smith, D.; Isaac, M.; Slassi, A. Heteropolycyclic compounds and their use as metabotropic glutamate receptor antagonists.U.S. Patent 2003055085 A1 March 20, 2003. 
43. Spink, E.; Ding, D.; Peng, Z.; Boudreau, M. A.; Leemans, E.; Lastochkin, E.; Song, W.; Lichtenwalter, K.; O'Daniel, P. I.; Testero, S. A.; Pi, H.; Schroeder, V. A.; Wolter, W. R.; Antunes, N. T.; Suckow, M. A.; Vakulenko, S.; Chang, M.; Mobashery, S. J. Med. Chem. 2015, 58(3), 1380-1389. https://doi.org/10.1021/jm501661f

44. Wiegand, I., Hilpert, K., \& Hancock, R. E. W. Nature Protocols 2008, 3(2), 163-175. https://doi.org/10.1038/nprot.2007.521

45. CLSI, Methods for Dilution Antimicrobial Susceptibility Tests for Bacteria that Grow Aerobically, Approved Standard, 9th ed., CLSI document M07-A9, Clinical and Laboratory Standards Institute, 950 West Valley Road, Suite 2500, Wayne, Pennsylvania 19087, USA, 2012.

46. Levi, M. I.; Suchkov, Yu. G.; Prohorov, V. Ya.; Terushkin, V. A. Dezinfekcionnoe-delo. 1999, 3, 21.

47. Sanchez, J. P.; Bridges, A. J.; Bucsh, R.; Domagala, J. M.; Gogliotti, R. D.; Hagen, S. E.; Sesnie, J. C. J. Med. Chem. 1992. 35, 361-367. https://doi.org/10.1021/im00080a023

48. Wentland, M. P.; Bailey, D. M.; Cornett, J. B.; Dobson, R. A.; Powles, R. G.; \& Wagner, R. B. J. Med. Chem. 1984, 27, 1103-1108. https://doi.org/10.1021/jm00375a003

49. Espinel-Ingroff, A.; Barchiesi, F.; Cuenca-Estrella, M.; Fothergill, A.; Pfaller, M. A; Rinaldi, M.; RodriguezTudela, J. L.; Verweij, P. E. J. Clin. Microbiol. 2005, 43, 4535-4540. https://doi.org/10.1128/JCM.43.9.4535-4540.2005

50. Espinel-Ingroff, A.; Barchiesi, F.; Cuenca-Estrella, M.; Fothergill, A.; Pfaller, M. A; Rinaldi, M.; RodriguezTudela, J. L.; Verweij, P. E. J. Clin. Microbiol. 2005, 43, 4535-4540. https://doi.org/10.1128/JCM.43.9.4535-4540.2005 